\title{
Metatarsophalangeal Joint 4
}

National Cancer Institute

\section{Source}

National Cancer Institute. Metatarsophalangeal/oint 4. NCI Thesaurus. Code C102324.

A condyloid synovial joint within the fourth digit of the foot connecting metatarsal with the proximal phalanx. 